\title{
Caracterización hidrodinámica del acuífero Pusuquí-San Antonio de Pichincha
}

\author{
Sandra Prócel \\ Escuela Politécnica Nacional. Facultad de Geología y Petróleos \\ sandra.procelg@epn.edu.ec \\ Renán Cornejo \\ Escuela Politécnica Nacional. Facultad de Geología y Petróleos \\ renan.cornejo@epn.edu.ec
}

Recibido: 01 de septiembre / Aprobado: 30 de noviembre 2017

\section{Resumen}

El uso y aprovechamiento del acuífero Pusuquí-San Antonio de Pichincha ejerce influencia sobre la recarga y la calidad del agua, por lo que es importante caracterizarlo, teniendo en cuenta que los acuíferos volcano-sedimentarios presentan alta complejidad por su geología, anisotropía y heterogeneidad. Durante las últimas décadas, el acuífero de Quito ha sido estudiado y monitoreado de manera continua, enfatizándose principalmente en el análisis de una posible continuidad hidráulica en los sectores de Pusuquí, Pomasqui y San Antonio de Pichincha. El objetivo de este estudio fue caracterizar el comportamiento y funcionamiento del acuífero Pusuquí-San Antonio de Pichincha, mediante el reconocimiento de las características hidrológicas, hidrogeológicas e hidroquímicas dominantes en el flujo subterráneo. La caracterización hidrodinámica identificó físicamente al acuífero, y determinó el modelo conceptual preliminar, para lo que se recurrió a investigaciones como: perforaciones, sondeos eléctricos verticales y campañas de monitoreo piezométrico y químico, con el fin de correlacionar los estratos, litologías y propiedades hidráulicas del sector con los determinados en el acuífero de Quito por Muñoz (2005). Así también se realizó el análisis de calidad del agua, con el objetivo de la captación del recurso para el consumo humano y doméstico. 
Palabras clave: acuífero Pusuquí-San Antonio, flujo hidrodinámico, aguas subterráneas.

\begin{abstract}
The use and exploitation of the Pusuquí-San Antonio de Pichincha aquifer exerts influence on the recharge and water quality, so it is important to characterize it, taking into account that the volcano-sedimentary aquifers present high complexity due to their geology, anisotropy and heterogeneity. During the last decades, the aquifer of Quito has been studied and monitored continuously, emphasizing mainly in the analysis of a possible hydraulic continuity in the Pusuquí, Pomasqui and San Antonio de Pichincha sectors. The objective of this study was to characterize the behavior and functioning of the Pusuquí-San Antonio de Pichincha aquifer, by recognizing the hydrological, hydrogeological and hydrochemical characteristics dominant in the underground flow. The hydrodynamic characterization physically identified the aquifer, and determined the preliminary conceptual model, for which research was used such as: drilling, vertical electric soundings and piezometric and chemical monitoring campaigns, in order to correlate the strata, lithologies and hydraulic properties of the aquifer sector with those determined in the Quito aquifer by Muñoz (2005). Likewise, the water quality analysis was carried out, with the objective of capturing the resource for human and domestic consumption.
\end{abstract}

Keywords: Pusuquí-San Antonio aquifer, hydrodynamic flow, groundwater. 


\section{Introducción}

$\mathrm{E}$ 1 desarrollo urbano e industrial de los sectores de Pusuquí, Pomasqui y San Antonio de Pichincha, conduce a un incremento de la demanda del recurso hídrico, el que actualmente es abastecido en un $85 \%$ por fuentes subterráneas ubicadas en el sector El Condado (Acuífero Norte de Quito) y el $25 \%$ restante por pozos y escasas vertientes de la zona (Departamento Acuífero de Quito, DAQ, 2004).

Tomando en cuenta que el abastecimiento actual está ligado a los pozos ubicados al Noroccidente de la ciudad y a la red de distribución de la EPMAPS (Unidad de mantenimiento electromecánico de distribución UMED, 2003), existió la necesidad de conocer, cuantificar y gestionar los recursos hídricos locales, que permitan satisfacer en el futuro, las necesidades de la población de esa zona.

Por lo expuesto, resultó imprescindible la ejecución de investigaciones y estudios de los acuíferos como posibles fuentes de suministro de agua y de esta manera aprovechar el recurso subterráneo. Bajo estas consideraciones, la Empresa Metropolitana de Alcantarillado y Agua Potable de Quito (EPMAPS), a través del Departamento Acuífero de Quito y la Escuela Politécnica Nacional, decidieron auspiciar el presente proyecto de investigación como una continuación del "Estudio Hidrogeológico y Modelación del nivel principal del Acuífero Centro Norte de Quito" (Muñoz, 2005), para llegar al conocimiento de las características hidrogeológicas del acuífero Pusuquí-San Antonio de Pichincha por considerarlo como una posible fuente complementaria de abastecimiento de agua potable para dicho sector.

\section{Área de estudio}

El área de estudio se localiza en la serranía ecuatoriana en el segmento correspondiente al valle Interandino Central (Quito-Guayllabamba). Comprende las localidades de Pusuquí, Pomasqui y San Antonio de Pichincha, entre las coordenadas 9992000 y 1000600 de latitud Sur y 780000-790000 de longitud Oeste.

Abarca un área total de $22 \mathrm{~km}^{2}$, con una longitud de aproximadamente $11 \mathrm{~km} \mathrm{y}$ un ancho promedio de $2 \mathrm{~km}$; se extiende desde la quebrada Pusuquí al Sur hasta la quebrada La Portada al Norte (figura 1b).

La principal vía de acceso es la avenida Manuel Córdova Galarza, que constituye el enlace de la ciudad de Quito con las poblaciones de Pusuquí, Pomasqui, San Antonio de Pichincha y hacia el Occidente con Calacalí. De esta carretera se derivan varios caminos lastrados que conectan a la población de San Antonio con la de Tanlahua, en sentido Nor-Noreste. Así también existen caminos secundarios y senderos que recorren los flancos del Casitagua y Catequilla, lo que permite tener facilidades de acceso a la zona de estudio. 
El área de estudio está definida por la presencia de dos grupos de elevaciones ubicadas sub-paralelamente. Al Occidente la cadena montañosa está formada de Sur a Norte por el Casitagua (3.519 msnm; constituye la elevación de mayor altura en la zona de estudio), el Tilingón (3.057 msnm), San Rafael (3.135 msnm) y Padre Rumi (3.255 msnm). Estas elevaciones mantienen un rumbo aproximado Norte-Sur, que varía a una dirección Nor-noreste al Noroccidente, donde se encuentra el complejo volcánico Pululahua. Al Este la cadena montańosa está constituida de Sur a Norte por la meseta El Artesón $(2.838 \mathrm{msnm})$, seguida por una pequeña cordillera compuesta por las lomas: Velasco Carcelén, Catequilla $(2.633 \mathrm{msnm})$ y termina con la loma La Providencia $(2.320 \mathrm{msnm})$. Esta cadena montañosa tiene un rumbo aproximado Norte-Sur y es la responsable del aislamiento del valle de Pusuquí-San Antonio con respecto al valle de Guayllabamba. En la zona de estudio, la mayor altura llega a los $2.600 \mathrm{msnm}$ en la quebrada Pusuquí y la menor es de 2.200 msnm en la quebrada La Portada (figura 1a y $1 b$ ).
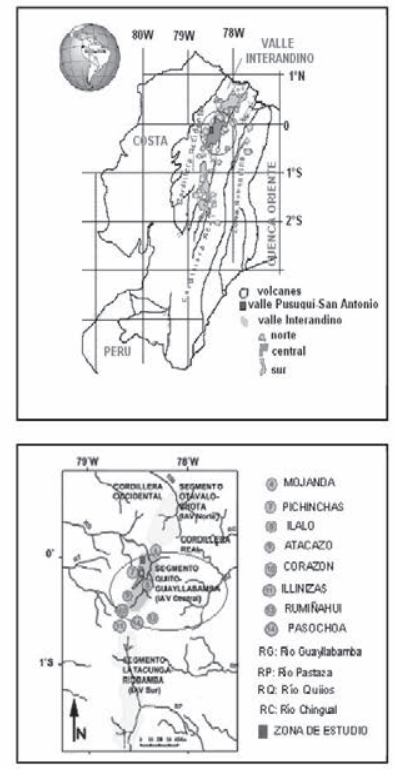

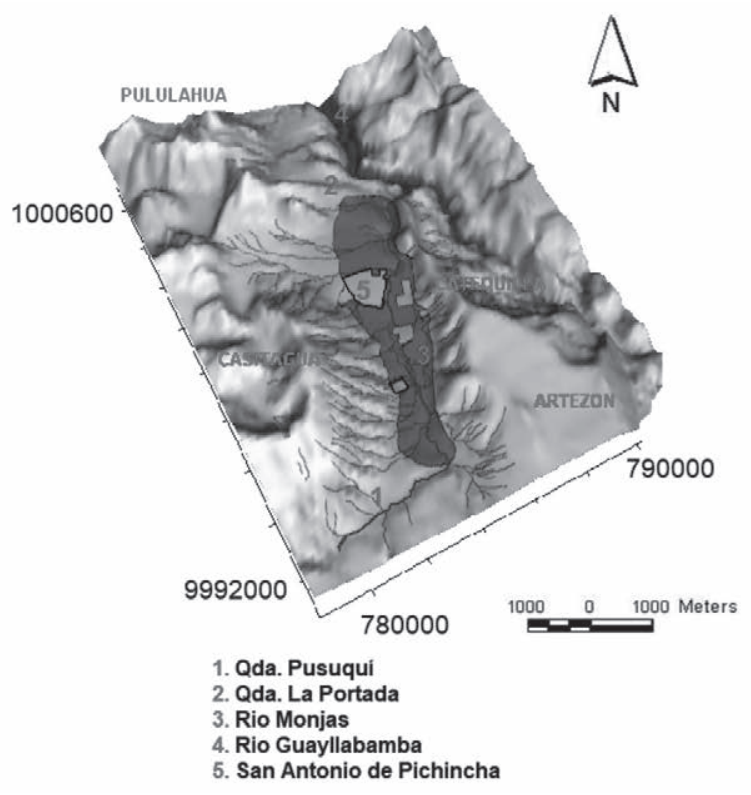

Figura 1. a) Valle Interandino Central, modificado de Villagómez, 2003; b) Ubicación del área de estudio. 
En lo que respecta al clima, este corresponde al ecuatorial mesotérmico semiárido temperado (Pourrut, 1995), con mayores precipitaciones en los meses de marzo y abril $(71,7 \mathrm{~mm} ; 59,6 \mathrm{~mm})$, en contraste con los meses de julio y agosto, donde alcanza un valor mínimo de $1,5 \mathrm{~mm}$. Las temperaturas promedio están en los $16^{\circ} \mathrm{C}$, (INAMHI, Estación San Antonio de Pichincha), teniendo como valores máximos y mínimos medios de $17,6^{\circ} \mathrm{C}$ y $14,5^{\circ} \mathrm{C}$, respectivamente (figura 2).

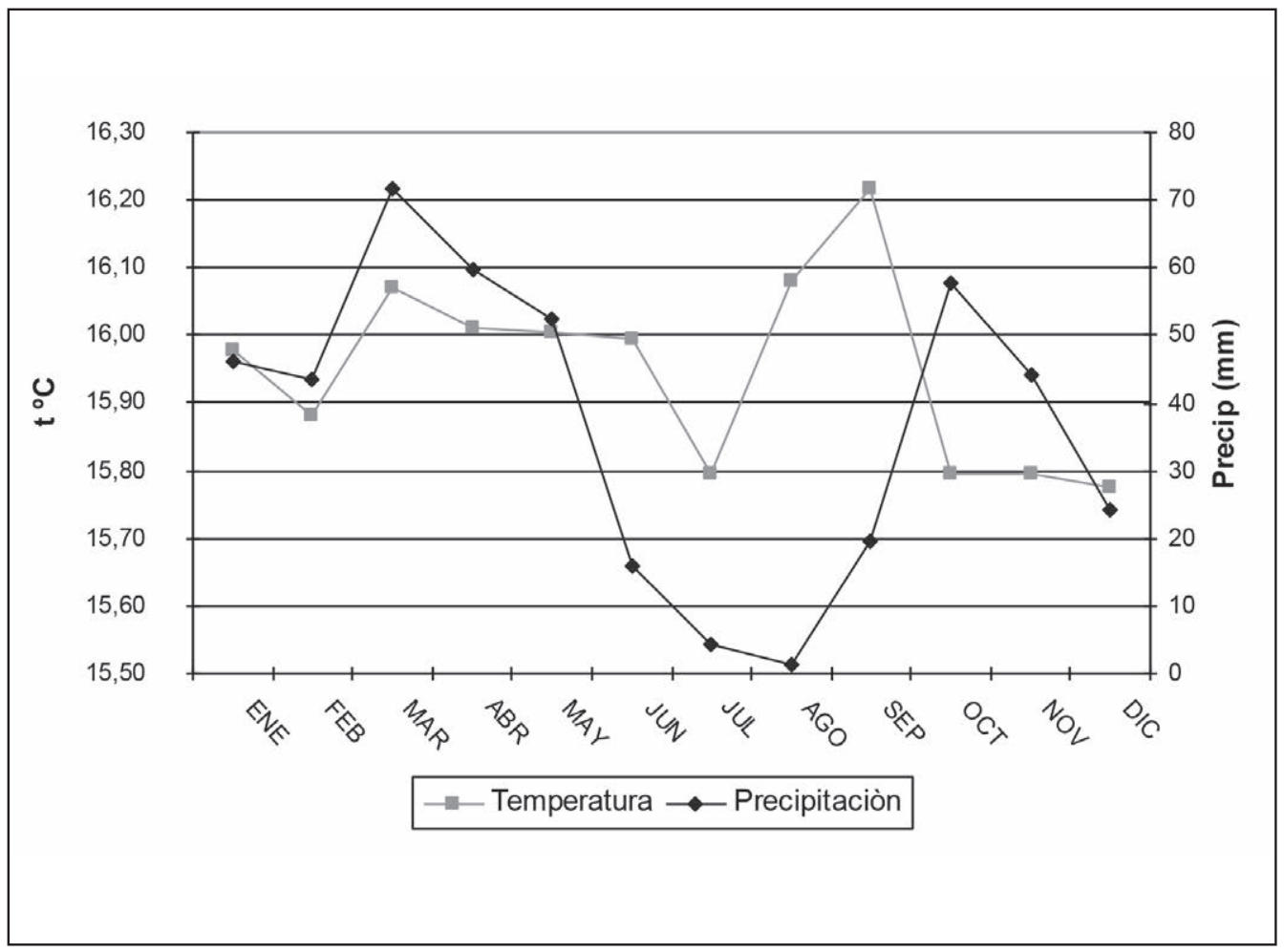

Figura 2. Relación de la precipitación y la temperatura en la zona de estudio.

El drenaje principal constituye el río Monjas-San Antonio, que la atraviesa longitudinalmente en dirección norte-noreste. A este río confluyen aproximadamente 25 quebradas que permanecen secas la mayor parte de tiempo, especialmente las situadas en la parte central de la cuenca. El río Monjas-San Antonio, se origina en las estribaciones del volcán Rucu Pichincha, los caudales registrados en un período de cuatro años (2002-2005) desde la estación El Colegio hasta la estación San Antonio de Pichincha (Unidad Ejecutora de Proyectos e Hidrología de la EPMAPS) oscilan entre $1,1 \mathrm{~m}^{3} / \mathrm{s}$, en época de sequía hasta $1,7 \mathrm{~m}^{3} / \mathrm{s}$ en época de sequía moderada a baja, sin llegar a lluviosa (figura 3). 


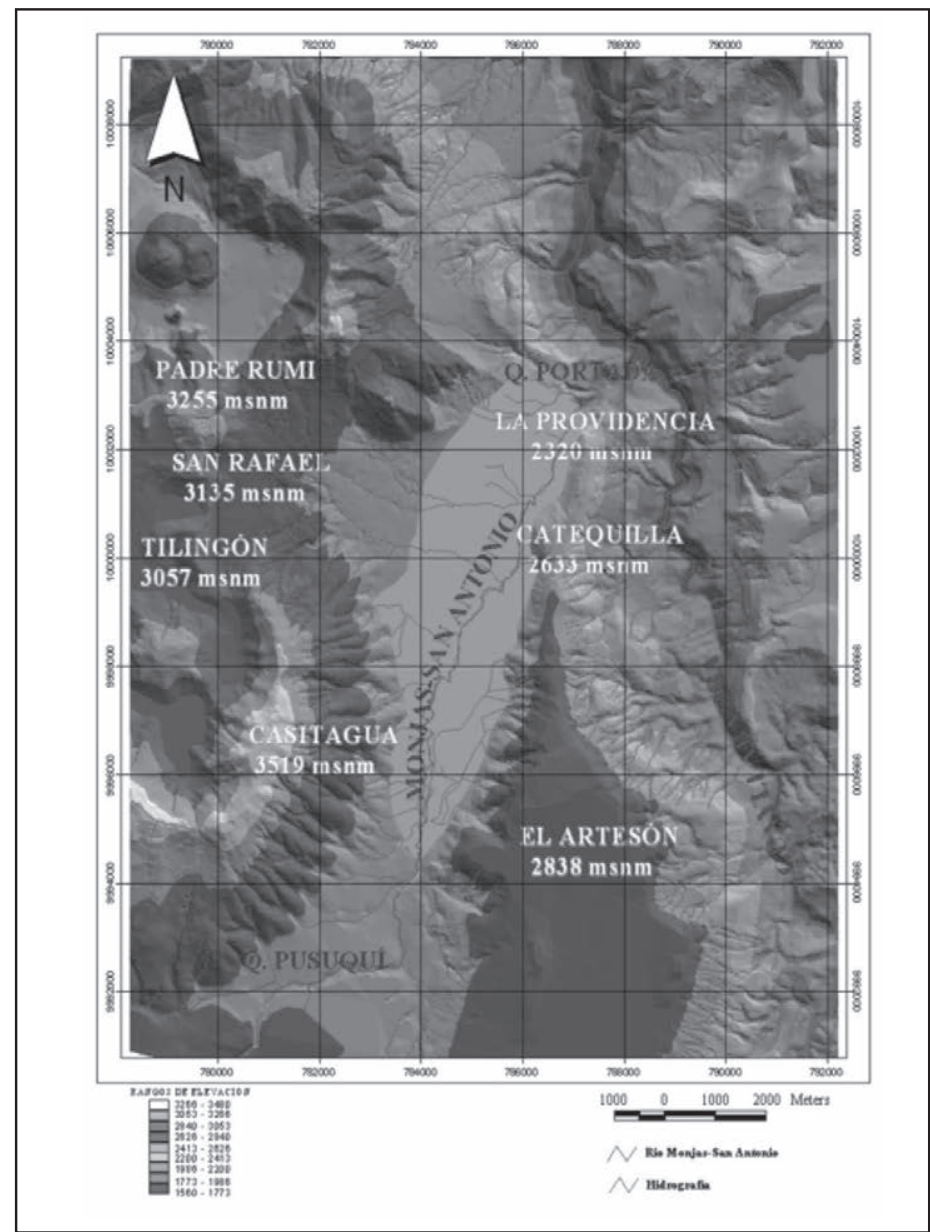

Figura 3. Drenaje de la zona de estudio.

\section{Métodología}

El presente trabajo fue la continuación del estudio de la Modelación del nivel principal del acuífero Centro-Norte de Quito (Muñoz, 2005) y comprendió la ejecución del modelo hidrodinámico del acuífero Pusuquí-San Antonio de Pichincha, usando la información hidrometereológica, geológica, hidrogeológica y química disponible para el área de estudio.

La información bibliográfica y cartográfica publicada en mapas topográficos (1:25.000), geológicos (1:25.000) y proyectos de titulación de Andrade (2002), Villagómez (2003) y Muñoz (2005) fue recopilada, analizada y digitalizada en una misma escala (1:25.000). Se interpretaron fotografías aéreas (escala 1:60.000) y se efectuaron levantamientos estratigráficos de campo, inventarios de fuentes hídricas, campañas de monitoreo químico y medición de niveles piezométricos. 
Los datos hidrológicos que se utilizaron están registrados en cuatro estaciones meteorológicas (Cotocollao, El Condado, Calderón y San Antonio de Pichincha). Los registros de estas estaciones fueron homogenizados en el rango de 17 años (1980-1997), para obtener los valores de precipitaciones medias anuales para cada estación. Cabe resaltar que la estación San Antonio de Pichincha, fue tomada como referencia para dicha homogenización. La precipitación media multianual fue determinada mediante una regresión lineal que compara este parámetro con la altura, con lo que se obtuvo el mapa de isoyetas. El mismo análisis fue realizado para los valores de temperatura y la obtención del mapa de isotermas.

Para la estimación del balance medio mensual preliminar en la zona de estudio, se aplicó el método establecido por Thornthwaite determinado en 1948. Este método (basado en ecuaciones empíricas) calcula evapotranspiración potencial mediante la ecuación:

$$
E_{m}=16\left(10 \frac{T}{I}\right)^{a}
$$

Donde: $\mathrm{E}_{\mathrm{m}}$ es la evapotranspiración potencial mensual en $\mathrm{mm}$; para un mes ficticio de 30 días y una insolación teórica durante 12 de las 24 horas del día; T la temperatura media mensual, expresada en ${ }^{\circ} \mathrm{C}$; I el índice calórico anual, obtenido de la suma de índices mensuales (i) y se expresa con la ecuación:

$$
\begin{aligned}
& I=\sum_{1}^{12} i \\
& i=\left(\frac{T}{5}\right)^{1.514}
\end{aligned}
$$

$$
a=675 \times 10^{-9} I^{3}-771 \times 10^{-7} I^{2}+1972 \times 10^{-5} I+0.49239
$$

En coordenadas logarítmicas, las curvas representativas de la ecuación de la evapotranspiración potencial, son rectas correspondientes a lugares y climas diferentes.

La información estratigráfica, provino de los trabajos realizados por Andrade (2002), Villagómez (2003) y Muñoz (2005), así como de los registros litológicos de las perforaciones de los pozos de explotación construidos entre 1978-2005 por la EPMAPS y empresas consultoras (Agroperfotadora, Hidroperforadora, Serviagua, Captagua y Asubsa). Esta información se complementó con columnas estratigráfi- 
cas, investigaciones geofísicas, perforaciones de exploración con recuperación de testigos y ensayos puntuales de infiltración. Estas investigaciones, permitieron redefinir la estratigrafía de la zona de estudio, e integrar el modelo conceptual.

En lo que respecta a la información hidrogeológica, esta procedió de los registros y cálculos realizados para nueve pozos de explotación, a pesar de que las pruebas de bombeo no determinaron el nivel acuífero captado. Por esta razón se recurrió a redefinir los parámetros hidrogeológicos por varios métodos, con el fin de compararlos con la litología y utilizar los más certeros.

Los datos hidrogeoquímicos provinieron de los análisis a diez muestras de agua, tomadas a lo largo del acuífero en estudio; se recogieron muestras de cuatro pozos y seis vertientes, en cuatro campañas de monitoreo químico, realizadas entre el 2004 al 2007. El proceso estuvo a cargo del Laboratorio de Control y Calidad de la EPMAPS. Las muestras se sometieron a dos análisis: microbiológico y fisicoquímico. Con el primero se determinó si el agua fue contaminada por bacterias, microorganismos o heces fecales, mientras que con el segundo, se establecieron los aspectos físicos como: aspecto, color, material sedimentario, partículas en suspensión y sustancias dañinas para la salud; a más de los aniones y cationes más frecuentes (Ca, $\mathrm{Mg}, \mathrm{Na}, \mathrm{K}, \mathrm{Al}, \mathrm{Fe}, \mathrm{Mn}, \mathrm{Zn}$ ).

En el campo se efectuaron las determinaciones de: conductividad eléctrica, potencial hidrógeno y sólidos disueltos, mientras que en el laboratorio se determinó: alcalinidad total, bicarbonatos, calcio, cloruros, color, dureza, magnesio, nitritos, nitratos, oxígeno disuelto, sulfatos, turbiedad, sílice, coliformes totales, carbono orgánico total, aluminio, arsénico, hierro, manganeso, potasio, sodio, zinc. Debido a que los valores de las sustancias contenidas en el agua, son normadas se comparó los resultados de los análisis de las cuatro campañas, con los límites máximos permisibles establecidos en el Texto Unificado de Legislación Ambiental Secundaria (TULAS, publicado en el Registro Oficial del 31 de marzo del 2003), para aguas de consumo humano y doméstico que solo requieren desinfección para su potabilización.

Para los análisis de las campañas del 2006 y 2007, se comparó los límites establecidos en la Norma Técnica Ecuatoriana (NTE INEN 1108, publicada en el Registro Oficial No 231 del 17 de marzo del 2006), instaurada para aguas de consumo humano y doméstico en los sistemas de abastecimiento público y privado a través de redes de distribución y tanqueros.

Cabe mencionar que los resultados de las campañas 2004, 2006 y 2007, estuvieron incompletos, por lo que los resultados obtenidos, sirvieron para comparar las sustancias reportadas con los límites admisibles para cada una de ellas.

Los diagramas hidroquímicos, se vieron limitados a los resultados del muestreo de la campańa del 2005. Se obtuvieron los resultados de cuatro pozos y seis vertientes. Se plotearon los resultados de los análisis, usando el programa Aquachem 4.0, con lo que se estableció la clasificación hidrogeoquímica del agua, a la que posteriormente se la comparó con la clasificación realizada para el proyecto Acuífero de Quito, para determinar semejanzas y diferencias. 


\section{Resultados y discusiones}

\section{Hidrometeorología}

En el área de estudio los parámetros hidrometorologicos muestran un déficit de infiltración. La evapotranspiración de $572.43 \mathrm{~mm}$ corresponde al $97.8 \%$ de la precipitación media mensual en el período de 17 años; el escurrimiento superficial tiende a cero, consecuentemente, un 2.2\% corresponde al aporte a la infiltración (tabla 1). Cabe resaltar que el escurrimiento superficial, no se estimó por mediciones de lluvias y crecidas simultáneas, debido a la falta de información de la intensidad de las precipitaciones y duración de las mismas, por lo que se estimó el porcentaje a partir del balance hídrico mensual considerando el déficit de la lluvia y los excedentes (agua que no puede ser retenida en el suelo y que se escapa a la escorrentía superficial o subterránea) mes a mes.

Debido a que la evapotranspiración real es muy alta (97.8\% de la precipitación) se verificó el método de cálculo utilizado en el balance medio mensual. Se realizó un análisis de sensibilidad para la evapotranspiración calculada por el método de Thornthwaite, modificando inicialmente la temperatura en un $\pm 10 \%$. En ese análisis se modificó la precipitación en $\pm 10 \%$ en el mismo modelo numérico. El porcentaje (10\%) corresponde al común utilizado en las variaciones de periodos secos a lluviosos (Departamento Acuífero de Quito, comunicación personal).

Tabla 1. Parámetros hidrometeorológicos en el área de estudio

\begin{tabular}{cccccccccccccc}
\hline Parámetro & Ene & Feb & Mar & Abr & May & Jun & Jul & Ago & Sep & Oct & Nov & Dic & Anual \\
\hline ETP & 69.63 & 62.26 & 70.38 & 67.62 & 69.63 & 67.62 & 68.14 & 70.38 & 69.08 & 68.14 & 66.18 & 68.14 & 817.2 \\
$\mathbf{P}$ & 50.25 & 55 & 83.36 & 90.83 & 57.29 & 21.29 & 9.85 & 12.19 & 39.45 & 72.99 & 55.2 & 37.72 & 585.4 \\
P-ETP & -19.4 & -7.26 & 12.98 & 23.21 & -12.3 & -46.3 & -58.3 & -58.2 & -29.6 & 4.85 & -11 & -30.4 & -232 \\
Delta R & 0 & 0 & 12.98 & 23.21 & -12.3 & -10.9 & 0 & 0 & 0 & 4.85 & -4.85 & 0 & \\
R & 0 & 0 & 12.98 & 23.2 & 10.86 & 0 & 0 & 0 & 0 & 4.85 & 0 & 0 & \\
ETR & 50.25 & 55 & 70.38 & 67.62 & 69.63 & 32.15 & 9.85 & 12.19 & 39.45 & 68.14 & 60.05 & 37.72 & 572.4 \\
Def & 19.38 & 7.26 & 0 & 0 & 0 & 35.47 & 58.29 & 58.19 & 29.63 & 0 & 6.12 & 30.42 & 244.8 \\
Exc & 0 & 0 & 0 & 12.99 & 0 & 0 & 0 & 0 & 0 & 0 & 0 & 0 & 12.99 \\
Q(mm) & 0 & 0 & 0 & 6.49 & 3.25 & 1.62 & 0 & 0 & 0 & 0 & 0 & 0 & \\
Q(m3/s) & 0 & 0 & 0 & 0.06 & 0.03 & 0.01 & 0 & 0 & 0 & 0 & 0 & 0 & 0.01 \\
\hline
\end{tabular}

ETP: Evapotranspiración potencial de Thornthwaite $(\mathrm{mm})$

P: Precipitación media, calculada para la zona de infiltración directa.

R: reserva máxima disponible, remanente de agua existente en el suelo, escurrimiento superficial

ETR: Evapotranspiración real $(\mathrm{mm})$

Def: Déficit de agua

Exc: Exceso de agua

Q: Caudal escurrido 
Como resultado, los porcentajes de evapotranspiración, escorrentía e infiltración no variaron significativamente, con relación a los valores obtenidos (tabla 1); se obtuvo rangos de porcentaje de evapotranspiración que oscilan entre 99,1-95,3\% de la precipitación para la zona de estudio (tabla 2).

Tabla 2. Porcentajes de evapotranspiración, escorrentía, infiltración para el análisis de sensibilidad del método numérico aplicado

\begin{tabular}{cccccc}
\hline Parámetro & Cond.Iniciales & $\begin{array}{c}\text { Temperatura } \\
\text { aumentada } \\
\text { en un } \mathbf{1 0} \%\end{array}$ & $\begin{array}{c}\text { Temperatura } \\
\text { disminuida en } \\
\text { un } \mathbf{1 0} \%\end{array}$ & $\begin{array}{c}\text { Precipitación } \\
\text { aumentada } \\
\text { en un } \mathbf{1 0} \%\end{array}$ & $\begin{array}{c}\text { Precipitación } \\
\text { disminuida } \\
\text { en un } \mathbf{1 0} \%\end{array}$ \\
\hline Evapotranspiración & 97.8 & $98.80 \%$ & $96.10 \%$ & $95.30 \%$ & $99.10 \%$ \\
Escorrentía & $0.00 \%$ & $0.00 \%$ & $0.00 \%$ & $0.00 \%$ & $0.00 \%$ \\
Infiltración & $2.20 \%$ & $1.20 \%$ & $3.90 \%$ & $4.70 \%$ & $0.90 \%$ \\
\hline
\end{tabular}

La tabla 2 corrobora el buen manejo del método matemático de cálculo utilizado para la determinación de la evapotranspiración real. Sin embargo, por la alta tasa de evapotranspiración obtenida (tabla 1), se recurrió a analizar los parámetros que intervienen en la infiltración natural, la que está influenciada por dos tipos de condiciones: la precipitación, que en el caso del valle Pusuquí-San Antonio es baja y la textura y estructura del suelo, lo que determina la capacidad de campo del mismo.

Debido a la baja capacidad de campo y al índice de infiltración, la mayor parte del agua infiltrada no se queda retenida en el suelo, por lo que se puede asumir que no aporta mayormente a la evapotranspiración, de tal forma que la evapotranspiración real calculada por el método de Thornthwaite puede no ajustarse a las condiciones reales, ya que este método tiene limitaciones en el cálculo; estas se deben a que: i) el período de tiempo estimado para el cálculo de los excedentes (un mes) es muy largo para este caso, ya que la capacidad de campo del suelo es baja; e ii) los métodos de cálculo (métodos matemáticos, en el método de Thornthwaite) utilizados, manejan fórmulas con mayor validez en las zonas geográficas donde fueron extraídas, pudiendo proporcionar mayores errores en otras regiones, dependiendo de la diferencia de las características climatológicas entre el área analizada y el área que se tomó como estándar para la aplicación del método. Estos errores son corregidos con mediciones de campo de la evapotranspiración y correcciones numéricas, que no se realizaron en este trabajo. 


\section{Balance hidrico}

El balance hídrico, consideró los ingresos y salidas de agua en la zona de estudio. Los ingresos se cuantificaron tomando en cuenta la infiltración directa debido a la precipitación, la presencia de volcanosedimentos que favorecen a la infiltración y la percolación de las aguas provenientes de las lluvias hacia los principales niveles acuíferos. Se estimó la infiltración directa en $283.343 \mathrm{~m}^{3}$ / año; evaluada a partir del $2.2 \%$ de la precipitación media multianual (tabla 3 ), para el área de la zona de acumulación $\left(22 \mathrm{~km}^{2}\right)$. Escurrimiento subterráneo proveniente del acuífero del Centro-Norte de Quito, estimado en 17.699.545 $\mathrm{m}^{3}$ /año (basado en caudales de explotación de pozos y vertientes, así como del caudal de acumulación del acuífero Centro Norte de Quito; Muñoz, 2005); éste se registra como descarga de dicho acuífero y constituye la recarga al acuífero Pusuquí-San Antonio de Pichincha (tabla 3). Tomando en cuenta las recargas expuestas, se determinó un ingreso de 570 l/s (tabla 3).

En las pérdidas totales del acuífero se consideraron los caudales que resultan de vertientes (basado en los aforos y estimaciones de caudales en el campo) y pozos bombeados, además del drenaje natural, con lo que se obtuvo 548 1/s (tabla 2).

La tabla 3 compara el caudal de recarga o ingreso estimado al acuífero y el caudal de descarga o pérdidas. La diferencia entre estos caudales estaría en un porcentaje de error del 6.3\%, este valor es bajo dentro del rango de error de la incertidumbre que resulta de las limitaciones de los datos. Tomando en cuenta que para la determinación del balance medio mensual, se estimaron valores medios anuales, considerando que a largo plazo, el acuífero tiene almacenamiento prácticamente constante debido a que las recargas en los años lluviosos, se equiparan con las recargas menores en los años secos.

Tabla 3. Balance hídrico en el área de estudio

\begin{tabular}{|c|c|c|}
\hline \% de infiltración en la zona directa o de acumulación. & 2,2 & \\
\hline Precipitación media multianual o infiltración directa $(\mathrm{mm})$ & 585,42 & \\
\hline área de infiltración directa $\left(\mathrm{km}^{2)}\right.$ & 22,00 & \\
\hline área de infiltración directa $\left(\mathrm{m}^{2)}\right.$ & 22000000 & \\
\hline Recarga 1.1 (m³/año) & $283.343,28$ & $8.98 \mathrm{~L} / \mathrm{s}$ \\
\hline \multicolumn{3}{|l|}{ 1.2.- Recarga acuifero de Quito } \\
\hline Descarga del acuífero de Quito, tomado de Muñoz (2005) en ( $\mathrm{m}^{3} /$ año) & $17.699 .545,00$ & $561,25(\mathrm{~L} / \mathrm{s})$ \\
\hline Recarga al acuífero Pusuquí-San Antonio (m³/ańo) & $17.699 .545,00$ & $570,23(\mathrm{~L} / \mathrm{s})$ \\
\hline Total Volumen de Recarga $(1.1+1.2)$ ( $\mathrm{m}^{3} /$ año $)$ & $17.982 .888,28$ & \\
\hline
\end{tabular}




\begin{tabular}{|c|c|c|}
\hline \multicolumn{3}{|l|}{ 2.1 Pozos } \\
\hline Pozos de operación, a cargo de la EMAAP-Q (L/s) & \multicolumn{2}{|l|}{26} \\
\hline Pozos privados $(\mathrm{L} / \mathrm{s})$ & \multicolumn{2}{|l|}{49,07} \\
\hline Suma de caudales de pozos privados y a cargo de la EPMAPS (L/s) & \multicolumn{2}{|l|}{75,06} \\
\hline \multicolumn{3}{|l|}{ 2.2 Vertientes } \\
\hline Pusuquí, Pailluco (L/s) & \multicolumn{2}{|l|}{14,00} \\
\hline Vertientes estimadas: Hacienda Oasis 1 y $2(\mathrm{~L} / \mathrm{s})$ & \multicolumn{2}{|l|}{6,00} \\
\hline $\begin{array}{l}\text { VSAP.1 Deslizamiento; VSAP.2 Deslizamiento; VSAP.3 Deslizamiento } \\
\text { (galería); VSAP.4 Monjas frente piscinas; VSAP.5. Entrada hacienda. (L/s) }\end{array}$ & \multicolumn{2}{|l|}{16,00} \\
\hline Drenaje natural; caudal de acumulación (L/s) & \multicolumn{2}{|l|}{512} \\
\hline Total Volumen de Descarga (L/s) & \multicolumn{2}{|l|}{548} \\
\hline \multicolumn{3}{|l|}{ 3.- Balance Hidrico Acuifero } \\
\hline Total Volumen de Recarga ( $\mathrm{m}^{3} / \mathrm{año}$ ) & 17.982.888.28 & $0.57 \mathrm{~m}^{3} / \mathrm{s}$ \\
\hline Total Volumen de Extracción (m³/año) & 17.281.172.80 & $0.54 \mathrm{~m}^{3} / \mathrm{s}$ \\
\hline Diferencia entre la recarga y la descarga $\left(\mathrm{m}^{3} / \mathrm{s}\right)$ & 0.03 & $\mathrm{~m}^{3} / \mathrm{s}$ \\
\hline
\end{tabular}

\section{Modelo de circulación de las aguas subterráneas}

En el área de estudio, el acuífero, se caracteriza por tener una configuración alargada (aproximadamente $11 \mathrm{~km}$ ) y estrecha, con un ancho de aproximadamente 2 $\mathrm{km}$. Está contenido en el relleno volcanosedimentario de la subcuenca del mismo nombre, en la que se diferenciaron tres formaciones geológicas:

Depósitos Casitagua, los que se encuentran a partir de los $100 \mathrm{~m}$ de profundidad, su espesor es desconocido ya que ninguna perforación alcanzó la base de estos depósitos. De acuerdo a las perforaciones exploratorias Pusuquí y Valle San Antonio de Pichincha (Vsap-1), corresponden a material variado, con secuencias de limos arenosos, arenas limosas; gravas, bloques andesíticos, flujos de lava (figura 4). El tercer nivel acuífero podría encontrarse en esta formación, a partir de los $120 \mathrm{~m}$, su espesor es desconocido, ya que la perforación con mayor profundidad (Vsap-1) no logró llegar hasta la base de los depósitos Casitagua. A los 120 m se observó (perforación Vsap-1) un flujo de lava andesítica, muy fracturada de aproximadamente $10 \mathrm{~m}$ de espesor; sin embargo, ninguna perforación caracterizó a este nivel, sus parámetros y espesor son desconocidos.

Formación Cangahua: con un espesor promedio de $70 \mathrm{~m}$, corresponde a limos arenosos y arenas limosas intercaladas por lapilli de pómez y cenizas finas (figura 4), además de lentes de arena, grava y bloques de composición andesítica que se encuentran entre los 80-95 m de profundidad. En esta formación se encuentra el segundo 
nivel acuífero. Las perforaciones de exploración y explotación además de los sondeos eléctricos verticales, reportaron lentes de arena, grava y bloques de composición andesítica con resistividades de 17 a 44 ohmios-metro. Este nivel se encuentra entre los 75 y $100 \mathrm{~m}$ de profundidad y se halla sobreyacido por una capa semiconfinante que corresponde a limos arenosos de aproximadamente cinco metros de espesor (figura 4).

Depósitos y flujos Pululahua: con un espesor variable entre 60 y $70 \mathrm{~m}$. Son estratos constituidos de limos arenosos, arenas limosas, arenas medias y gruesas con intercalaciones de lapilli de pómez (figura 4). Se distribuyen en toda la zona de estudio, haciéndose más potente a partir de la quebrada Colorada, con un espesor promedio de $100 \mathrm{~m}$ (figura 4). A los $40 \mathrm{~m}$ de profundidad, se encuentran arenas gruesas y medias con intercalaciones de lapilli de pómez, con resistividades de 18 a 72 ohmios-metro (figura 4). Estos volcanosedimentos componen el nivel acuífero superior con un espesor promedio de $30 \mathrm{~m}$.

A pesar de la variedad litológica, discontinuidades en la estratificación y acuñamientos presentes en el área de estudio, se consideró al acuífero Pusuquí-San Antonio como multicapa, con un espesor que supera los $210 \mathrm{~m}$ (profundidad de la perforación exploratoria Vsap-1), compuesto por dos niveles acuíferos, constituidos en distintas capas, depósitos y formaciones que están interrelacionados hidráulicamente (figuras 5 a y 5b).

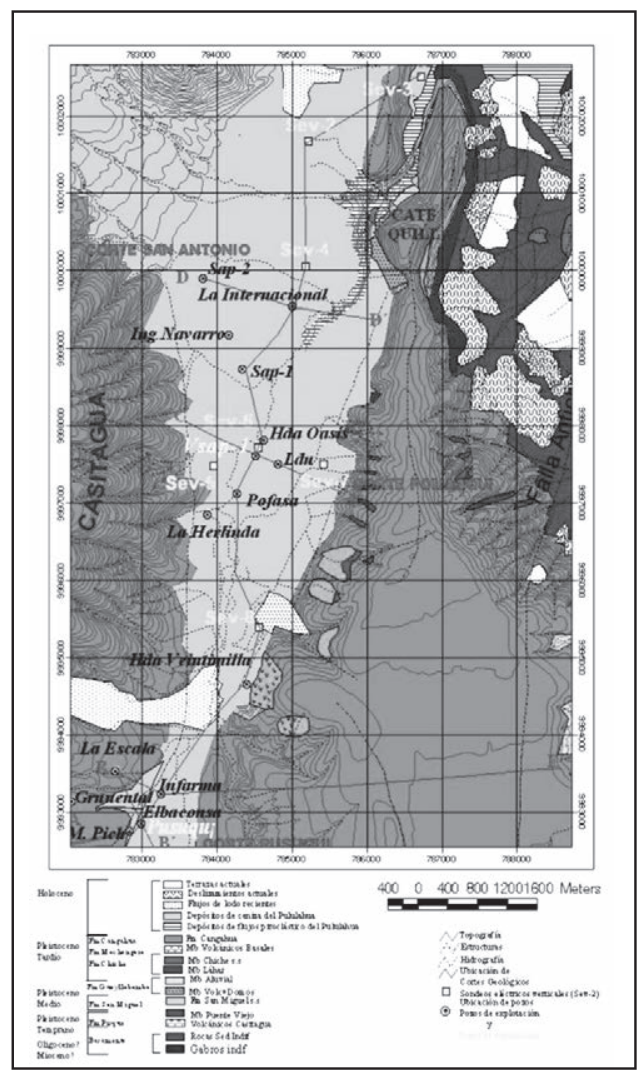

Figura 4. Geología del área de estudio. 

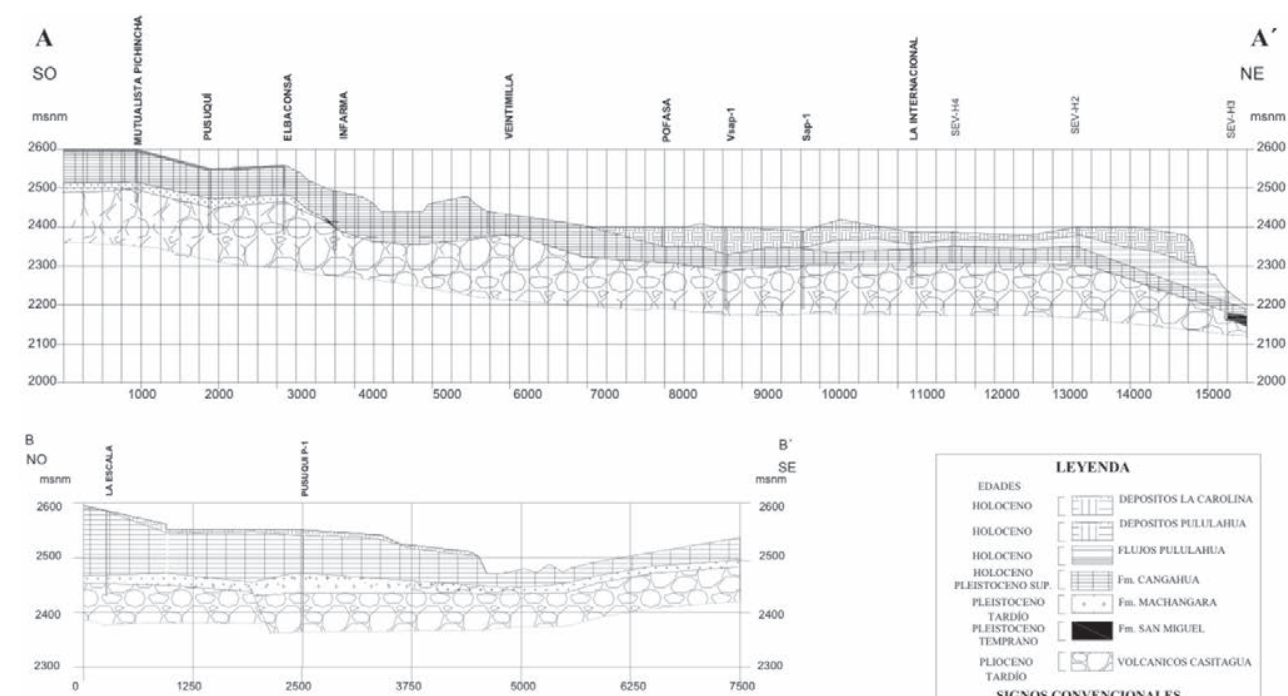

Figura 5a. Secciones hidrogeológicas del área de estudio.

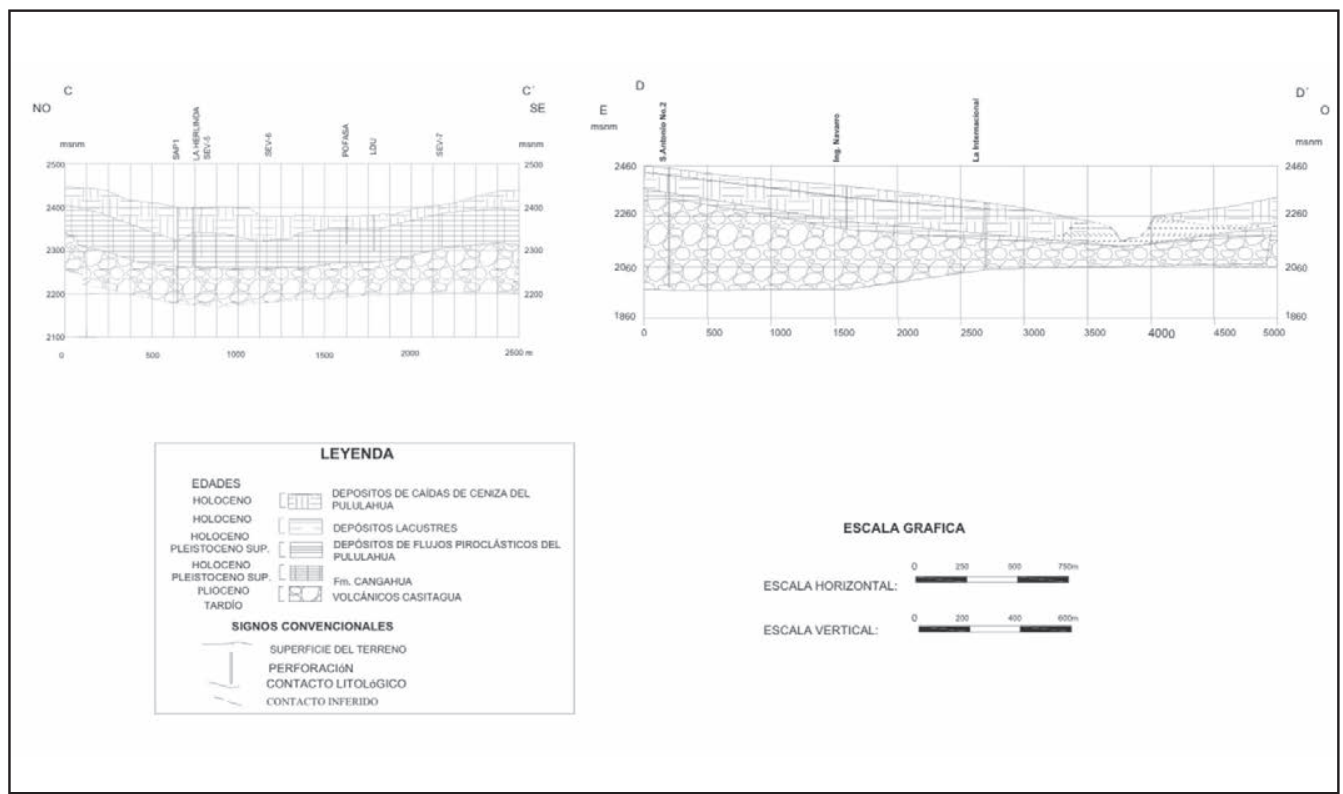

Figura 5b. Secciones hidrogeológicas del área de estudio. 
Es importante destacar que en el área de estudio, se evidenció además un acuífero colgado, ubicado en los depósitos lacustres localizados en el sector de San Antonio de Pichincha, en las piscinas municipales (figura 5a y 5b). Entre los depósitos de conductividad hidráulica aproximada de $1.7 \mathrm{~m} /$ día, se encuentra un estrato de menor conductividad hidráulica, compuesto de cenizas, limos y principalmente turba (0,001-0,07 m/día; De Miguel Fernández, 1999); en él se encuentran las vertientes VSAP-1, VSAP-2, VSAP-3, VSAP-4, VSAP-5 (figuras 6a y 6b).

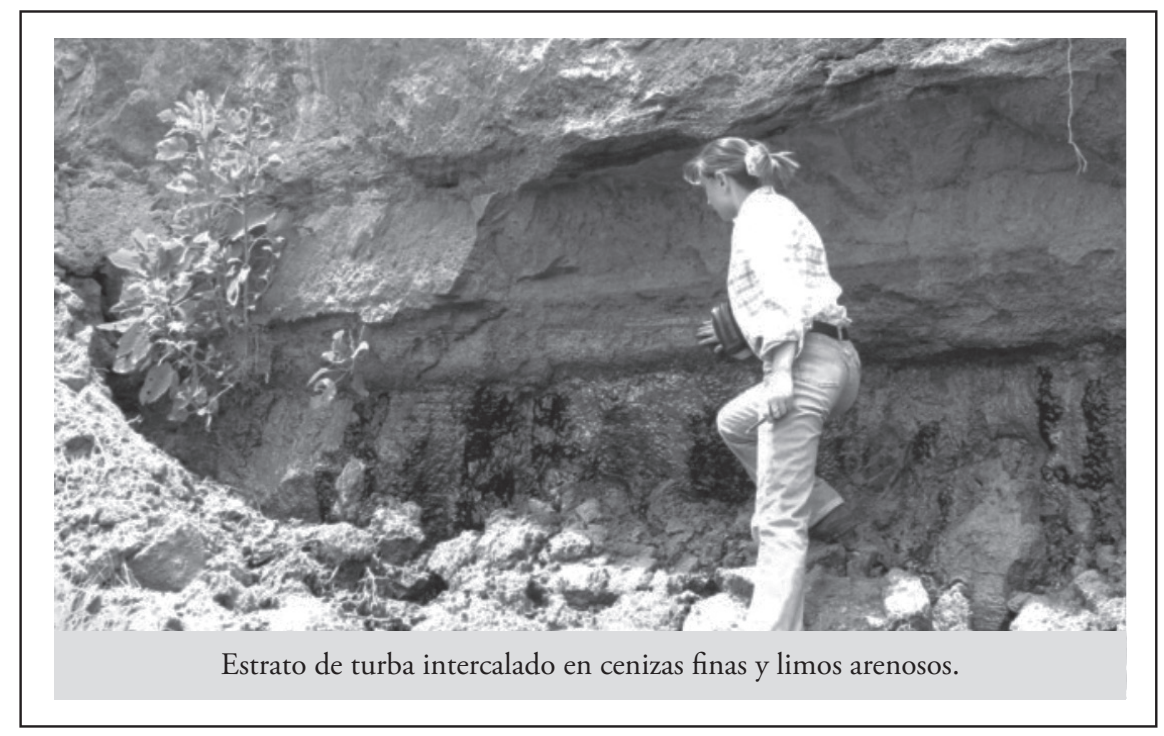

Figura $\mathbf{6} \boldsymbol{a}$. Vertientes y estrato de turba ubicadas en San Antonio de Pichincha (sector de las piscinas municipales).

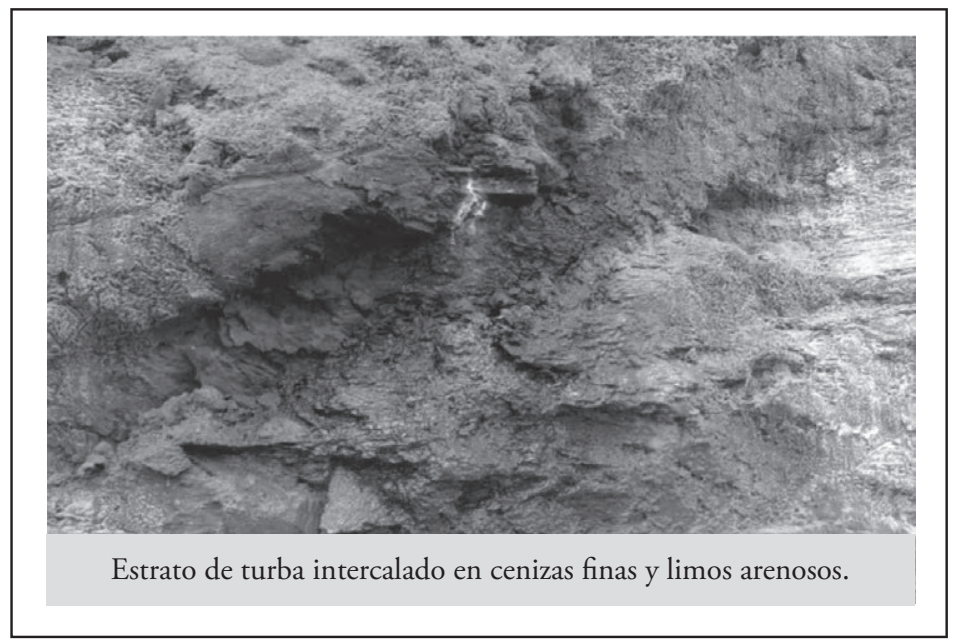

Figura 6b. Vertientes y estrato de turba ubicadas en San Antonio de Pichincha (sector de las piscinas municipales, al margen derecho del río) Monjas-San Antonio. 
Las pruebas de bombeo no aportaron la argumentación necesaria para los cálculos de los parámetros hidrogeológicos de los niveles acuíferos, ya que se realizaron con una duración menor a 12 horas, lo que provocó abatimientos inestables y de poca profundidad.

Las aguas subterráneas que se encuentran en el segundo nivel, a una profundidad de 75 a $100 \mathrm{~m}$, presentan niveles de agua que ascienden hasta $42,5 \mathrm{~m}$ de profundidad, es decir el nivel piezométrico está por encima del contacto superior del segundo nivel acuífero (perforación Vsap-1), por lo que se consideró al agua de este nivel como artesiana, del acuífero semiconfinado.

Sin embargo, los valores de conductividad hidraúlica obtenidos en base a las pruebas efectuadas por el coeficiente de filtración en la perforación Vsap-1, están alrededor de $1.8 \mathrm{E}-5 \mathrm{~cm} / \mathrm{seg}$, es decir $0.016 \mathrm{~m} /$ día, para una profundidad de 75 a 80 $\mathrm{m}$ (informe de sondeos mecánicos y eléctricos EPMAPS, 2005), igualmente para la perforación Pusuquí se obtuvieron valores inferiores a 0.1m/día, para $111-150 \mathrm{~m}$ de profundidad (informe de sondeos mecánicos y eléctricos, EPMAPS, 2005). Según De Miguel (1999), estos valores corresponden a limos y arcillas areno-limosas, lo que difiere con la litología registrada en las perforaciones exploratorias, las que reportan a arenas, gravas y brechas.

Se recalcularon los valores de conductividad hidraúlica, aplicando la metodología sugerida y establecida por De Miguel (1999), es decir el cálculo de los parámetros hidrogeológicos mediante regímenes de bombeo estacionario y cuasiestacionario. Para la recuperación de niveles al culminar los bombeos; los valores obtenidos están por debajo de $0.001 \mathrm{~m} /$ día (anexo III, cálculo de parámetros hidrogeológicos), lo que correspondería a arcillas, arcillas margosas, argilitas (De Miguel,1999). Estos resultados tampoco corresponden con la litología descrita en el acuífero.

Por las razones expuestas, se recurrió a asumir los parámetros hidrogeológicos (conductividad hidráulica, transmisividad) con base en la literatura (Freeze y Cherry, 1979), y las pruebas de infiltración realizadas en el sector, tomando en cuenta la litología existente en cada estrato, confirmada con los testigos de perforación.

Para el primer nivel acuífero se asumió una conductividad hidráulica entre 1.4$1.7 \mathrm{~m} /$ día, lo que corresponde a limos arenosos y arenas limosas. Para el segundo nivel acuífero se asumió 1.7-2.8 m/día, lo que corresponde a arenas limosas, arenas de grano fino a medio.

En cuanto a la transmisividad, se obtuvo para el primer nivel acuífero, $42-51 \mathrm{~m}^{2} /$ día, considerando una conductividad hidráulica de 1.4-1.7 m/día y un espesor promedio de $30 \mathrm{~m}$. Para el segundo nivel acuífero, se consideró un espesor promedio de $25 \mathrm{~m}$, con lo que se obtuvo $42.5-70 \mathrm{~m}^{2} /$ día de transmisividad.

La determinación de la profundidad del nivel piezométrico, constituyó una dificultad, ya que la mayoría de los pozos fueron perforados sin aislar los distintos niveles acuíferos, por lo que no se pudo establecer el nivel piezométrico para cada nivel acuífero.Sin embargo, se realizaron tres campañas de medición de niveles para 
la medición. Se contó con dos pozos (Pusuquí y Vsap-1) en cada campaña. Para el sector de Pusuquí, la profundidad media del nivel piezométrico, obtenida fue entre 75-90 m, mientras que en Pomasqui y San Antonio se localiza entre 30-54 $\mathrm{m}$. Tomando en cuenta las mediciones de la campaña del 07/07/2006, se ploteó el mapa piezométrico (figura 6) en el que se observa que las líneas de flujo tienen una dirección preferencial del Sur hacia el Noreste.

Las direcciones de flujo establecidas para el acuífero de estudio, son coincidentes con la continuación de las líneas de flujo establecidas para el acuífero Centro Norte de Quito, ya que en este último, tienen una tendencia hacia el Noreste (Muñoz, 2005).

Por lo expuesto, el modelo conceptual establecido para el acuífero Pusuquí-San Antonio de Pichincha, consta de dos niveles acuíferos interconectados, agrupados en el acuífero multicapa. El tercer nivel acuífero, no determinado en este estudio, debido a la falta de información, se supone estaría a partir de $120 \mathrm{~m}$ de profundidad. El segundo nivel acuífero, consiste en un acuífero semiconfinado, que se encuentra a partir de los $75 \mathrm{~m}$ de profundidad, con un espesor promedio de $25 \mathrm{~m}$, ubicado en la formación Cangahua. El primer nivel acuífero, consiste en un acuífero libre, se encuentra a partir de los $40 \mathrm{~m}$ de profundidad, con un espesor medio de $30 \mathrm{~m}$, que corresponde a los depósitos y flujos Pululahua (figura 7).

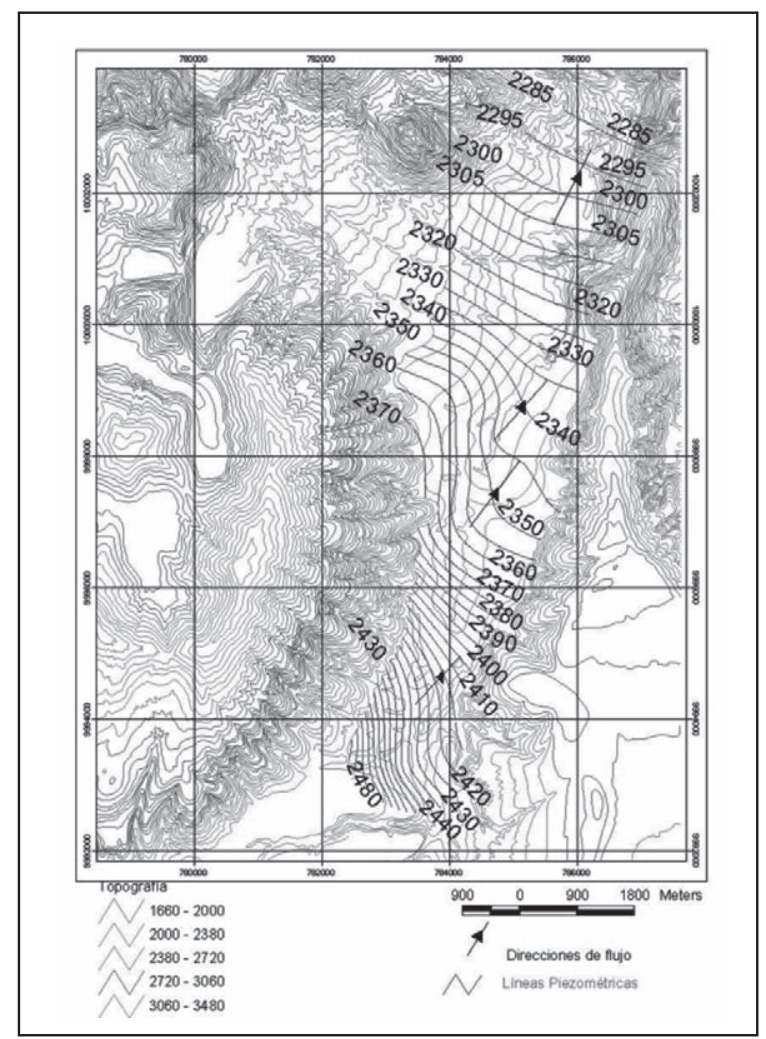

Figura 6. Mapa piezométrico del área de estudio. 
La zona de recarga principal, se ubica en el extremo sur del acuífero y corresponde al acuífero Centro Norte de Quito. Adicionalmente la infiltración proviene de las precipitaciones en el sector, que a pesar de ser bajas constituyen una recarga al acuífero.

Este modelo, visualiza la dependencia y conexión del acuífero de Quito con el acuífero Pusuquí-San Antonio de Pichincha. Los dos presentan condiciones y características geológicas e hidrogeológicas y direcciones de flujo muy similares.

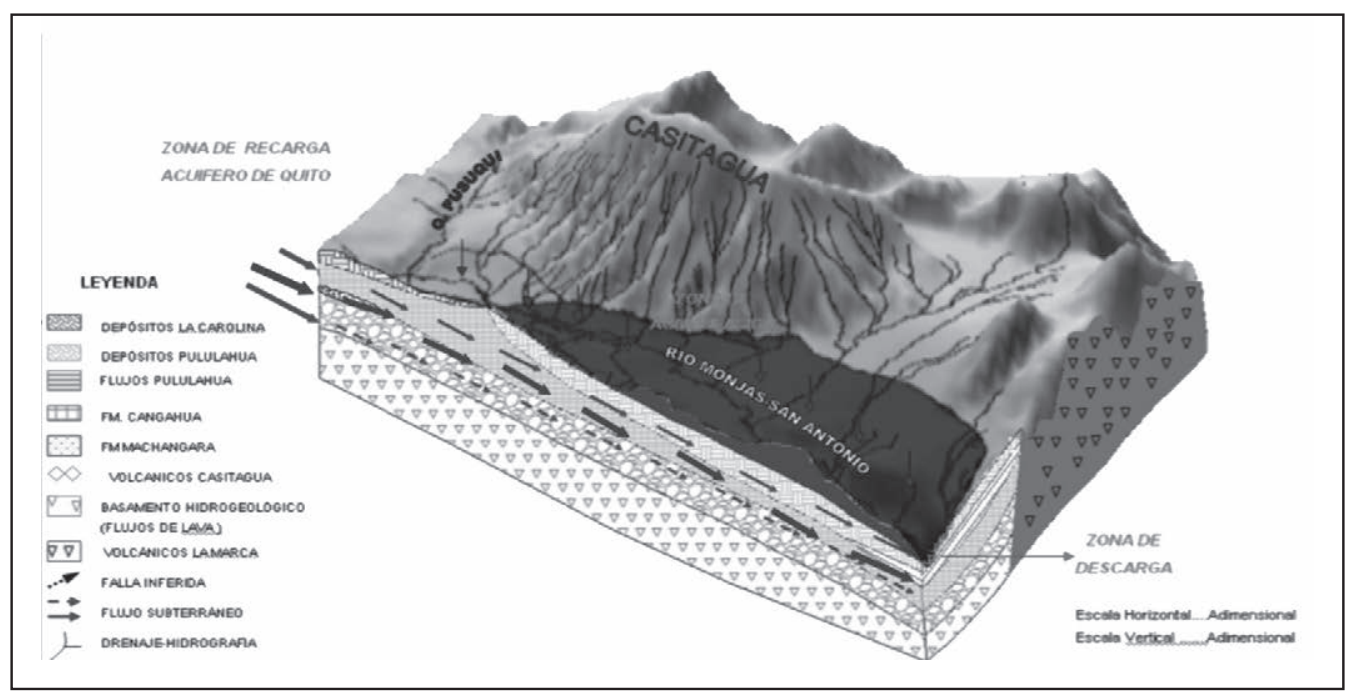

Figura 7. Modelo conceptual del acuífero.

\section{Hidrogeoquímica}

Con base en los resultados de los análisis físico-químicos, de las muestras tomadas en la campańa del 2005, se elaboraron los diagramas de Piper para cada una de las muestras, para lo que se utilizó el programa Aquachem 4.0, lo que permitió establecer el tipo de agua en la zona de estudio.

Las aguas del acuífero Pusuquí-San Antonio de Pichincha son de tipo bicarbonatadas, cálcico-magnésicas. La vertiente SAP-5 y el pozo Pofasa, presentan una mayor concentración cálcica, sin alterar la tendencia general de las muestras. Tomando como referencia las muestras de la campaña del 2005 y 2007, ubicadas en el sector de Pomasqui (LDU, Vsap-1) y San Antonio de Pichincha (PSAN ANTONIO1) se observó que las muestras del sector sur del acuífero (Pomasqui), contienen más sodio que las ubicadas en San Antonio de Pichincha, que muestran una composición más cálcica (figura 8). Esto se debe a que al norte del acuífero las rocas de los estratos que conforman los niveles acuíferos, son más ácidas (rocas más claras, mayor presencia de plagioclasas ácidas: albita, oligoclasa y cuarzo; denominadas como andesitas ácidas; Andrade, 2002) estas rocas, hacen que las aguas se enriquezcan en calcio y magnesio. 


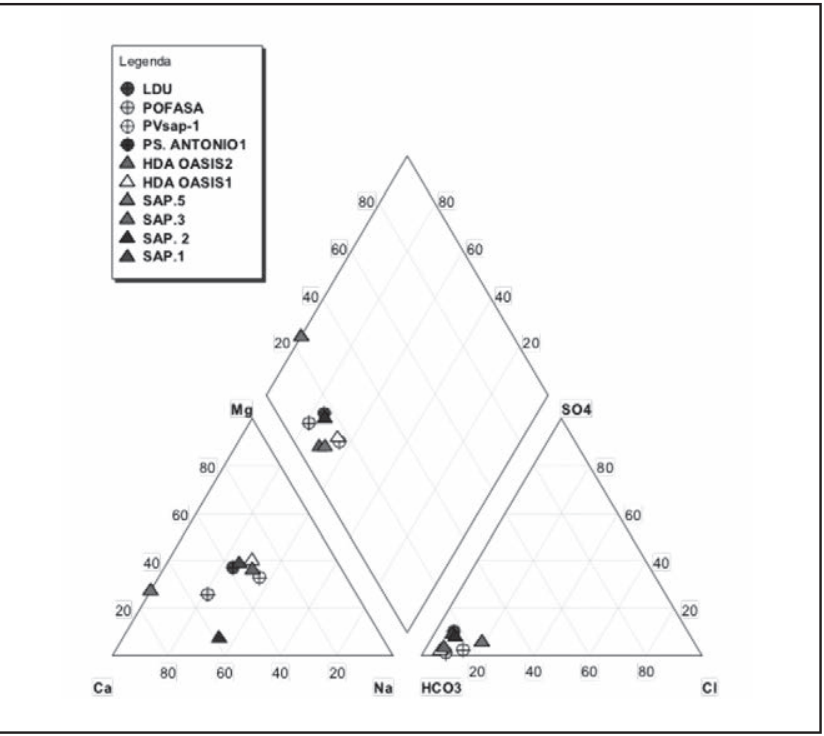

Figura 8. Diagrama de Piper para los pozos y vertientes muestreados en la campaña del 2005, en el acuífero Pusuquí- San Antonio de Pichincha.

Tomando en cuenta la relación de las aguas subterráneas con respecto a su mineralización, se observó que las concentraciones de sólidos totales disueltos, en las campańas del $2004 \mathrm{al}$ 2007, se conservaron en el tiempo con valores que están por debajo de $1 \mathrm{gr} / \mathrm{l}$, por lo que corresponden a aguas dulces (Martínez, 2005).

Considerando la concentración de iones hidrógeno, las campañas de muestreo del 2004 al 2007, indicaron valores de ph que varían de $6-8$ unidades, con lo que se demuestra que el agua tiene un comportamiento de aguas que varían de débilmente ácidas a débilmente básicas.

Según el análisis de calidad del agua, los datos de las campañas de monitoreo indican que: para las campañas realizadas por la EMAAP-Q, el 62\% de las muestras incumplen al menos por una vez la norma en los valores que corresponden al hierro y manganeso. Los máximos valores corresponden a las muestras que fueron tomadas en la zona de San Antonio de Pichincha (pozos: San Antonio-1 (PSAP-1), Liga Deportiva Universitaria (LDU) y la vertiente San Antonio de Pichincha No 4 (VSAP- 4) (tabla 4).

El incremento en el contenido del hierro y manganeso, se debe a que en el sector San Antonio de Pichincha, existe un estrato de turba (figura $5 \mathrm{a}$ y b), es decir alto contenido de carbón, lo que indica condiciones reductoras (anaeróbicas), las que se reflejan en los análisis físico-químicos con un alto contenido de dióxido de carbono; además de la ausencia de oxígeno disuelto.

El 46\% de las muestras incumplen la norma en coliformes totales, principalmente en la campańa del 2006, esto se debe a la presencia de materia fecal en las proxi- 
midades de las vertientes VSAP-4, VSAP-1 y vertiente Oasis. En lo que se refiere al pozo Vsap-1, el incremento está asociado a la contaminación del pozo con materia fecal, en el instante del muestreo.

Por lo expuesto, las muestras en el sector de San Antonio de Pichincha, son aptas para el consumo humano y doméstico. El incremento en el contenido del hierro y manganeso, produce una coloración amarillo-marrón de alta intensidad, sin causar toxicidad o peligro alguno; sin embargo, estas substancias pueden ser controladas por medio de tratamiento. Así también las muestras deberán ser sometidas a un tratamiento de desinfección por cloración, para evitar la presencia de coniformes totales.

Tabla 4. Resumen de los parámetros que incumplen las norma TULAS 2003, para las campañas (2004-2005) y la norma NTE para las campañas 2006-2007.

\begin{tabular}{|c|c|c|c|c|c|c|}
\hline $\begin{array}{c}\text { POZOS Y } \\
\text { VERTIENTES }\end{array}$ & $\begin{array}{c}\text { PARÁMETROS QUE } \\
\text { INCUMPLEN LA NORMA }\end{array}$ & $14 / 4 / 2004$ & $20 / 7 / 2004$ & 2005 & 2006 & 2007 \\
\hline Pofasa & STD, HIERRO & NR & SI & SI & $\mathrm{NO}$ & NR \\
\hline Hda Oasis & $\begin{array}{l}\text { TURBIEDAD, HIERRO, } \\
\text { MANGANESO }\end{array}$ & NR & NR & NO & NR & NR \\
\hline $\begin{array}{c}\text { P. Liga } \\
\text { Deportiva } \\
\text { Universitaria } \\
\text { LDU }\end{array}$ & $\begin{array}{l}\text { STD, HIERRO, MANGANESO, } \\
\text { COLOR, TURBIEDAD, } \\
\text { MANGANESO, STD, HIERRO, } \\
\text { MANGANESO, COLOR, } \\
\text { STD DUREZA, HIERRO, } \\
\text { MANGANESO, FOSFORO, ESCH. } \\
\text { COLI, DUREZA TOTAL }\end{array}$ & $\mathrm{NO}$ & $\mathrm{NO}$ & $\mathrm{NO}$ & NO & $\mathrm{NO}$ \\
\hline VSAP-1 & $\begin{array}{l}\text { COLOR, TURBIEDAD, STD, } \\
\text { HIERRO, MANGANESO, } \\
\text { COLIF. TOTALES, HIERRO, } \\
\text { MANGANESO, ESCH. COLI }\end{array}$ & SI & SI & $\mathrm{NO}$ & SI & NR \\
\hline VSAP-2 & $\begin{array}{l}\text { COLOR, TURBIEDAD, STD, } \\
\text { HIERRO, MANGANESO }\end{array}$ & NR & NR & $\mathrm{NO}$ & NR & NR \\
\hline
\end{tabular}




\begin{tabular}{|c|c|c|c|c|c|c|}
\hline VSAP-4 & $\begin{array}{l}\text { COLOR, TURBIEDAD, } \\
\text { HIERRO, MANGANESO, STD, } \\
\text { HIERRO, MANGANESO, } \\
\text { COLOR, TURBIEDAD, STD, } \\
\text { COLIF. TOTALES, HIERRO, } \\
\text { MANGANESO, COLOR, STD, } \\
\text { HIERRO, MANGANESO, } \\
\text { CARBONO ORGÁNICO, } \\
\text { DUREZA, COLIF. TOTALES. } \\
\text { ARSÉNICO }\end{array}$ & NO & NO & $\mathrm{NO}$ & NO & NR \\
\hline VSAP-5 & $\begin{array}{c}\text { COLOR, TURBIEDAD, STD, } \\
\text { HIERRO, MANGANESO }\end{array}$ & NR & NR & $\mathrm{NO}$ & NR & NR \\
\hline VERT.OASIS1 & COLIF. TOTALES & NR & NR & NO & NR & NR \\
\hline VERT.OASIS2 & COLIF. TOTALES & NR & NR & $\mathrm{NO}$ & NR & NR \\
\hline \multicolumn{7}{|c|}{ NR: no existe reporte de análisis } \\
\hline \multicolumn{7}{|c|}{ NO: cumple la norma } \\
\hline \multicolumn{7}{|c|}{ SI: cumple la norma } \\
\hline
\end{tabular}

\section{Conclusiones}

El modelo conceptual establecido para el acuífero Pusuquí-San Antonio de Pichincha, consta de dos niveles acuíferos. El nivel superior se ubica en los depósitos y flujos Pululahua, tiene un espesor medio de $30 \mathrm{~m}$ y se localiza a partir de los $40 \mathrm{~m}$ de profundidad. El segundo nivel acuífero, se halla a partir de $75 \mathrm{~m}$ de profundidad, tiene un espesor medio de $25 \mathrm{~m}$ y corresponde a la formación Cangahua. El nivel acuífero superior es libre, mientras que el segundo nivel acuífero es semiconfinado, los dos niveles están conectados hidráulicamente formando un acuífero multicapa. Las direcciones de flujo para el acuífero Pusuquí-San Antonio de Pichincha, son coincidentes con las líneas de flujo del acuífero Centro Norte de Quito, con tendencia hacia el Noreste.

Los parámetros hidrogeológicos para el acuífero son: 1.4-1.7 m/día para el primer nivel acuífero y 1.7-2.8 m/día para el segundo. La transmisividad, del primer nivel acuífero es 42-51 m²/día, considerando una conductividad hidráulica de 1.4-1.7 m/ día y un espesor promedio de $30 \mathrm{~m}$. Para el segundo nivel acuífero, se consideró un espesor promedio de $25 \mathrm{~m}$, con lo que se obtuvo $42.5-70 \mathrm{~m}^{2} /$ día de transmisividad.

El nivel piezométrico para el 07/07/2006 se ubicó a una profundidad entre 7590 m (2485-2470 msnm) en el sector de Pusuquí, mientras que en Pomasqui y San Antonio se localiza entre los 30-54 m (2.360-2.336 msnm).

Las aguas en la zona de estudio, son químicamente estables de tipo bicarbonatadas-cálcico-magnésicas, muy similar a las determinadas para el acuífero de Quito, que son de tipo bicarbonatadas magnésicas. Las aguas subterráneas, localizadas en el sector de San Antonio de Pichincha, muestran una composi- 
ción más cálcica que las localizadas en el sector de Pomasqui. Los estratos que conforman los niveles acuíferos, contienen rocas más ácidas, por lo que las aguas se enriquecen en calcio y magnesio.

La calidad físico-química y bacteriológica, determinó que el agua contenida en las localidades de Pusuquí y Pomasqui es apta para el consumo humano y doméstico, luego de ser tratadas con el proceso de cloración. En el sector de San Antonio de Pichincha, el incremento en el contenido del hierro y manganeso, produce una coloración amarillo-marrón de alta intensidad, sin causar toxicidad o peligro alguno; sin embargo, estas substancias pueden ser controladas por medio de tratamiento. Así también las muestras deberán ser sometidas a un tratamiento de desinfección por cloración, para evitar la presencia de coliformes totales.

El acuífero de Pusuquí-San Antonio de Pichincha representa la continuación del acuífero Centro Norte de Quito, la similitud de los estratos, la continuidad de la estratificación, los parámetros hidrogeológicos asumidos, las direcciones de flujo y el tipo de agua, garantizan dicha continuidad.

\section{Referencias}

Andrade, D. (2002). Estudio geovolcanológico del complejo volcánico Pululahua. Proyecto de titulación, Ingeniería en Geología, EPN, 186 pág.

De Miguel, C. (1999). Hidrogeología aplicada. Editorial Félix Varela, 453 pág.

EPMAPS. Unidad ejecutora de proyectos e hidrología. (2003). Registro de caudales del rio Monjas-San Antonio.

EPMAPS. (2003). Unidad de Mantenimiento Electromecánico de Distribución. Reporte de mantenimiento de pozos.

Villagómez, D. (2003). Evolución Geológica Plio - cuaternaria del Valle Interandino Central en Ecuador . Proyecto de titulación, Ingeniería en Geología EPN.

EPMAPS. Departamento Acuífero de Quito. (2004). Informe de sondeos mecánicos y eléctricos, sondeo P-1. Pusuqui. vol. 2 de 5.

EPMAPS. Departamento Acuífero de Quito. (2005). Informe de sondeos mecánicos y eléctricos, sondeo Vsap-1. San Antonio de Pichincha.

EPMAPS. Departamento Acuífero de Quito. (2005). Investigaciones de resistividad eléctrica en la exploración de aguas subterráneas.

Fotografías aéreas. (1983/02/04). Escala 1:60000, 1:20000, IGM, Instituto Geográfico Militar. Departamento de Fotografía Aérea. Rollo 86.

Martínez, D. (2005). Informe de consultoría. Análisis de la información hidrogeoquimica de los valles de los Chillos, Pifo-El Quinche y Pusuqui-San Antonio de Pichincha. Departamento Acuífero de Quito. EMAAP-Q

Muñoz, T. (2005). Modelación del nivel principal del acuifero de Quito. Proyecto de titulación. Ingeniería en Geología. EPN. 174 pág. 
Pourrut, P. (1995). Estudios de geografía: El agua en el Ecuador.

Freeze, R.A., Cherry, J. A. (1979) Groundwater. Englewood Cliffs, Prentice - Hall, p. 604.

Instituto Nacional Ecuatoriano de Normatividad, Ecuador (1998). NTE INEN 2169:98. Norma Técnica Ecuatoriana, Agua: Calidad del agua, muestreo, manejo y conservación de muestras.

Norma Ambiental y de descarga de efluentes (2003). Recurso Agua. Libro VI Anexo 1, publicado en el Registro Oficial del 31 de marzo del 2003.

Thornth waite, 1948 The Water Balance, Publications, In: Climatology, New Jersey: Drexel Institute of Technology, 104 págs. 